@CEDA/TU, 2017, US Library of Congress, Catalog Card No.: 79-915209, ISSN: 2091-0339

The Journal of Development and Administrative Studies (JODAS), Vol. 25(1-2), pp.83-94

\title{
Unmet Need for Family Planning among Currently Married Young Women in Nepal
}

\author{
Kamala Lamichhane ${ }^{1}$
}

\begin{abstract}
A high level of unmet need for contraception persists among currently married young women in Nepal. Evidences about unmet need for family planning and associated factors are not fully analyzed in the Nepalese context. Therefore, this study investigates the prevalence and determinants of unmet need for family planning among currently married young women in Nepal. This is an analytical cross-sectional study through secondary data analysis of the 2011Nepal Demographic and Health Survey women data-file. The analysis is based on 2,552 currently married young women aged 15-24 years. Logistic regression is used to assess the net effect of independent variables on dependent variable. Women's current age, number of living children, education level, occupation, women empowerment, castelethnic affiliation, and residence are independent predictors of unmet need. The odds of unmet need are significantly higher among the adolescents, rural, not empowered and not working young women. There is a need to strengthen income generating activities so as to improve their socio-economic status which will translate into female economic and social empowerment which enable them to discuss on sexual issues. Family planning programmes should be designed so as to address the unmet need of young women especially the rural adolescents.
\end{abstract}

Keywords: Reproductive health, Contraception, Determinants, Regression analysis, NDHS data.

\section{Introduction}

Unmet need for family planning is defined as the percentage of married or in-union women of reproductive age who want to stop or postpone childbearing but who report that they are not using any method of contraception to prevent pregnancy. Unmet need for family planning is useful for tracking progress in achieving the universal access to sexual and reproductive health-care services, including family planning (UN, 2017). Nearly every Asian country has experienced a drop in birthrate due to the widespread acceptances of family planning. However, national populations are expected to grow well into the next century because of population momentum - a consequence of the increasing numbers of adolescents and young people in the region.

The need for family planning services in Nepal was recognized as early as 1958 , when a private organization, the Family Planning Association of Nepal (FPAN), was established in Kathmandu. The central premise and rationale of family planning programme was to enable individuals, particularly, women and couples to exercise control over their own fertility. However, in the early 60s, as the Government gradually became more concerned about controlling the rapid population growth, the national perspective overrides the individual needs. Population explosion increasingly caused worry to the Government about their ability to provide adequate level of health, education and other social services. Many approaches and strategies to improve the programme and to increase the contraceptive prevalence rate had been adopted.

\footnotetext{
${ }^{1}$ Ms Lamichhane is a Lecturer at Central Department of Population Studies, Tribhuvan University, Kathmandu, Nepal
}

Corresponding mail: lamichhanekd@gmail.com 
In the area of family planning, the Government of Nepal aims to enable women and couples to attain the desired family size and have healthy spacing of childbirths by improving access to rights-based family planning services and reducing unmet need for contraceptives $(\mathrm{MoH}, 2015)$. To address the access to rights based family planning service, Nepal developed the Costed Implementation Plan (CIP) on family planning 2015 - 2020 which focuses on five strategic areas. They are Enabling Environment, Demand Generation, Service Delivery, Capacity Building and Research and Innovation. Through investment in these areas, the country aims to increase demand satisfied for modern contraceptives from 56 percent (Ministry of Health (MoH) [Nepal], New ERA and ICF International, 2012) to 62.9 percent and Contraceptive Prevalence Rate (CPR) for modern methods from 47 percent (CBS, 2015) in 2014 to 50 percent by 2020 (MoH, 2015). Likewise it aims to reduce unmet need for family planning from 25.2 percent in 2014 (CBS, 2015) to 22 percent which would allow the country to achieve a replacement level fertility of 2.1 births per women by 2021 (MoH, 2015). These targets may appear relatively modest but were chosen to reflect the context of a country that has witnessed impressive gains in family planning but has CPR that has been stagnant for some time in recent years and the unmet need for family planning continues to remain high (35 percent for aged 15-19 and 32.6 percent for aged 20-24 years in 2016) especially among young women (Ministry of Health (MoH) [Nepal], New ERA and ICF, 2017).

The Government of Nepal is committed to provide equitable access to voluntary family planning services based on informed choices by individuals and couples and particularly poor, vulnerable and marginalized people (MoH/DoHS, 2015/16). Young women may disproportionately experience unmet need for family planning due to their distinct fertility preferences associated with this stage of the life course. Alternately, they may experience higher levels of unmet need where they lack full knowledge of their options, access to services is lacking (particularly those designed for young people or for spacing needs generally), or where programs underestimate needs of youth (MacQuarrie, 2014). A high level of unmet need for contraception persists among currently married young women in Nepal. Evidences about unmet need for family planning and associated factors are not fully analyzed in the context of Nepal. Therefore, this study investigates the magnitude and determinants of unmet need for family planning among currently married young women in Nepal using the cross sectional data from Nepal Demographic and Health Survey, 2011. This paper is divided into five sections. The first section presents background to the current situation of unmet need among currently married women aged 15-24 years and its determining factors. Section two presents the brief review of literature. Third section describes the methodology adopted in the research including types of data, its source and nature and analytical technique. Section four deals analysis and interpretation of results. Discussion and conclusions of the research analysis are presented in section five.

\section{Review of Literature}

Use of contraception goes beyond demographic benefits. It offers better health, education and employment opportunities and social participation. The International Conference on Population and Development held in 1994 in Cairo has emphasised that family planning is one of the important strategies to improve women's reproductive, social and economic lives. Therefore, women need to have rights to decide when and what contraception to use (United Nations Population Fund [UNFPA], 2004).

Unmet need arises from a discrepancy between women's stated fertility preferences and their contraceptive behaviour. The existence of unmet need was first documented in developing countries in the late sixties after the collection of data on women's knowledge, attitudes and practices (KAP) of contraception, and their reproductive intentions (Westoff and Pebley, 1981). However, the concept has gained importance following the World Fertility Survey (WFS), Contraceptive Prevalence Survey (CPS) and more recently the Demographic Health Survey (DHS). 
Unmet need is a powerful concept for designing family planning programmes and has important implications for future population growth. The magnitude of unmet need and information on the characteristics of the unmet need population provide a more comprehensive measure of the expanded future demand for contraception (Ross, 1994). Unmet need also allows the estimation of the impact on fertility if this additional demand is met (Sinding, John \& Rosenfield, 1994).

Low uptake of the family planning methods or high unmet need for family planning is the major cause of unintended pregnancies and short pregnancy intervals in developing countries (Cleland \& Ali, 2004).Socio-cultural and structural barriers often prevent adolescents from achieving their reproductive desires, which can result in unintended and unhealthy pregnancies, among other outcomes. Family planning plays a vital role in preventing unintended pregnancies and reducing maternal and child mortality (Borda \& Winfrey, 2010). It promotes the health of mothers and children by lengthening pregnancy interval and helps to avoid financial, psychological, and health costs due to unintended pregnancies. However, following childbirth, many families overlook contraception due to a poor perception of pregnancy risks, difficulty in accessing services, and socio cultural issues (Ijadunola, Orji, Kuti, and Alabi, 2005 \& Vernon, 2009). Many factors such as geographical and financial access, provider bias, and poor method choice, lower status of women, legal restrictions, and fear of side effects act as a barrier to family planning use (Foran, 2011).

World Health Organization (2011) states that low contraceptive use among young women is often considered reflecting a desire to become pregnant, especially in settings where there is socio-cultural pressure to prove fertility.Most recently, while studying determinants of unmet need among women in rural Kenya, Nyauchi and Omedi (2014) found that marital status, current age, level of education of women, number of living children, employment status, region of residence, household wealth index and exposure to mass media communications significantly related to unmet need for spacing childbearing, limiting childbearing and total unmet need for family planning.

A study by Okech, Wawire \& Mburu (2011) found that among women who had knowledge about family planning services, 72 percent were using family planning services while 28 percent were not using the services. Based on the level of education of the respondents, the study found women with no formal education to be the least users of family planning while those with post-primary education qualifications had higher chances of using contraceptives. Ashford (2003) found the most educated women to have the lowest levels of unmet need, presumably because they are most able to act on their intentions. However, while studying new estimates for unmet need and demand for family planning, Westoff (2006) found an initial increase in unmet need with education and attributed it to the gap between increasing desire to control fertility and the ability to do so. The work of Ojakaa (2008) found that total unmet need to be 16 percent higher among women with primary education qualifications compared to those with no any education qualification tend to agree with this. Especially for spacing, where most, if not all teenagers lie, the study found women with primary educational qualifications to be more likely to have unmet need for spacing childbirths compared to those with post-primary educational qualifications.

Unmet need for contraception among young married women is often neglected both by researchers and service providers. A study conducted among young women observed that in India, where women continue to marry young, the greatest need for contraception is to postpone the first pregnancy. Young women's premarital awareness of sexual and 
reproductive matters, and specifically of contraceptive methods and services, determined their use of contraceptives to delay first pregnancy. Agency, spousal communication, and quality of sex education were also critical in enabling young women to delay first pregnancy by using contraceptive method (Jejeebhoy, Santhya, and Francis Zavier, 2014)

According to literature, diverse factors including age, marital status, level of education, religion, occupation, and household wealth have been found to be significantly associated to unmet need for family planning. Misconceptions and concern of the health risk associated to these methods influence contraceptive use in a significant way and therefore keep unmet need high especially among young married women. In Nepal, literature on this subject matter is still sparse and the determinants of unmet need among young women have not been clearly explained. In addition, little or no studies have clearly identified the above mention determinants to be true for young women in the Nepalese context.

Therefore, there is a need to explore and identify the variables that have strong influence on met and unmet need for family planning among young women in Nepal. The analysis result could be expected to fill the information gaps by understanding the different determinants of unmet need for family planning and help policy makers plan interventions aimed at reducing unmet need for family planning among young women Nepal.

\section{Methodology}

\subsection{Data Source and Sample}

This study is based on Nepal Demographic and Health Survey 2011 data set. The NDHS 2011 used two-stage stratified cluster sampling to select a representative sample of households. The primary objective was to provide national estimates with an acceptable level of precision for population characteristics such as fertility, contraceptive need and prevalence, and selected health indicators and infant mortality. The survey collected information on fertility, infant, maternal and child health, nutrition, knowledge of HIV/AIDS and other sexually transmitted infections (STIs) and family planning knowledge and use, source of modern contraception, contraception discontinuation and unmet need for family planning, that allows us to explore the relationship between women's demographic and socio economic status and their unmet need for family planning in Nepal.

The survey and data were collected from 12,674 women 15-49 years of age and the samples have nationwide representation. However, the samples used for this study consist of currently married young women aged 15-24 who were fecund, pregnant or amenorrheic. The data set consists of individual sampling weights for women, which were obtained by further correction for women's individual non response based on household sampling weights (Ministry of Health (MoH) [Nepal], New ERA and ICF International, 2012). Thus, 2,552 currently married young women aged 15-24 years are the main target population for the study.

The NDHS 2011 data set was downloaded from Macro International Inc website after making a request to do so from Macro International, USA. The data set was opened by the Statistical Package for Social Scientists (SPSS) software for windows version 16.0. Since young women are the unit of analysis, the data is transformed in a manner that each young women aged 1524 constituted a unit of observation. 


\subsection{Study variables}

\section{Dependent variables}

There are three dependent variables -unmet need for spacing, unmet need for limiting and total unmet need for family planning ( for bi-variate analysis) and one dependent variable (total unmet need) are used for this study. In the Nepal Demographic and Health Survey, women, who reported not wanting more children (limiters), or wanting to wait for two or more years before having another child (spacers) but were not using contraception, were categorized as having an unmet need for family planning. Pregnant women were considered to have unmet need for spacing or limiting if their pregnancy was mistimed or unwanted, respectively. Similarly, amenorrhoeic women were classified as having unmet need if their last birth was mistimed or unwanted. According to data the response for unmet needs was categorized into 9 categories. This is recorded into dichotomous variable as $1=$ Unmet need and $0=$ No unmet need. Unmet need to space and unmet need to limit are recoded as 1 and other responses are recoded as 0 .

\section{Independent variables}

Twelve independent variables i.e., age, age at first marriage/cohabitation, number of living children, presence of son, education, occupation, household wealth index, asset ownership, household decision-making status, caste/ethnicity, ecological region and place of residence are used as predictors in order to check for their significance as unmet need for family planning determinants.

Women's age is categorized into broad groups, 15-19 and 20-24 years; age at first marriage into two categories, less than 20 and 20 and above; number of living children, into three groups (no living children, one, and two or more living children); presence of son into two categories as no son at all and having at least one son. Education is grouped into three levels (no education, primary education and secondary and above education); women occupation is categorized into three (not working, working in agriculture and working in non agriculture). Wealth index is a measure of the socioeconomic level for a household. It is categorized into three: poorer,' medium and richer households. Women empowerment is measured in the domestic sphere by making women empowerment index using four types of household decision making role. The variable, women's participation in household decision making, comes from the question "Who in your family makes decisions about (1) healthcare for yourself, (2) large household purchases, (3) visits to family and/or relatives, and (4) use of husband earning?" Responses are coded as: respondent alone; respondent and husband/partner; respondent and someone else; husband/partner alone; someone else; others. These responses are first dichotomized to create dummy variables for each of the four decision making domains. For each domain, the variable is coded as 1 if the wife had any say in that decision, and 0 if the wife had no say. Using these four questions, a composite index is developed to assess women's involvement in household decision-making. The index ranges from 0 to 4 . Each woman is then classified into two groups on the basis of her total score. Women who are not involved and involved at least in two decisions of the above four questions are categorized as 'Not empowered' (score 0-2), and women involved in 3-4 decision are considered as 'Empowered'. Four categories of religion - Brahmin/Chhetri, Janajati, Dalit and Others are used. Ecological zone is synonymously used to refer to the ecological belt, which entailed mountain, Hill, and Tarai. Type of place of residence referred 
to the place where the respondent stayed at the time of interview. It is categorized as either rural or urban.

\subsection{Method of data analysis}

Multivariate statistical analysis is applied to estimate the likelihood of a young woman experiencing unmet need given the prevailing social, economic, cultural, geographic and demographic condition. The logistic regression model allows the estimation of the occurrence of an outcome due to the effect of several explanatory variables. It allows for the adjustment of many explanatory variables and controlling for many confounders at the same time as it enables easy detection of the interaction between explanatory factors.

Analyses are done at two levels: bivariate and multivariate levels. Bi-variate analysis is used to analyze the relationship between two selected variables. Selected independent variables are cross tabulated with the dependent variables to analyze one to one association between these variables. Chi-square test is used to test the significance of association between two variables. Variables are then included in the multi-variate analysis based on the association at the bivariate level. Multivariate logistic regression analysis is done to identify the independent effects of explanatory variables on the outcomes of interest. As the dependent variables are measured in binary scale (yes or no) and most of the independent variables are categorical variables, logistic regression analysis is the best method to analyze the data. Moreover, logistic regression does not assume linearity of the relationship between each independent and dependent variables and it does not require normally distributed variables. Two models are shown at the multivariate level. In Model I each independent variables are analyzed separately so as to explain the individual effect of each independent variable with dependent variable (gross effects)and Model II explains the net effect of each of the variable on the likelihood of experiencing unmet need for family planning, controlling for the effects of other selected explanatory variables (net effects). Odds ratios and 95\% confidence intervals are reported in the study.

\subsection{Strengths and limitations}

NDHS data provides nationally representative findings; however, women who were not using contraceptives, but were abstaining from sexual intercourse, were not considered to be protected from unintended pregnancy; however, considering changing sexual patterns and sexual activity during postpartum period (Borda \& Winfrey, 2010; Desgrees \&Brou, 2005), this study believes that these groups can be considered to have an unmet need. The NDHS data set did not enable an exploration of differences in the uptake of family planning between women who did and did not use maternal, newborn, and child health services or received advice/counseling on family planning around the time of the birth of the previous child. Unmet need for family planning is influenced by both demand and supply factors. But the NDHS is a household survey and does not include health service data; hence this study is only limited to the demand side factors and is not considered the supply side factors like the availability of family planning methods or counseling, provider competency, or quality of care. The study is limited to quantitative analysis, and some qualitative research would provide a full understanding of factors affecting unmet need of family planning among young women. 


\section{Data analysis and presentation}

\subsection{Unmet need for family planning among young women: Bivariate analysis}

Table 1: Percentage of currently married young women age 15-24 with unmet need for spacing, unmet need for limiting and total unmet need for family planning by background characteristics

\begin{tabular}{|c|c|c|c|c|}
\hline Background Characteristics & $\begin{array}{l}\text { Unmet need } \\
\text { for Spacing }\end{array}$ & $\begin{array}{l}\text { Unmet need } \\
\text { for limiting }\end{array}$ & $\begin{array}{c}\text { Total } \\
\text { Unmet Need }\end{array}$ & $\begin{array}{l}\text { Total Number } \\
\text { of women }\end{array}$ \\
\hline \multicolumn{5}{|l|}{ Age groups } \\
\hline $15-19$ & 37.5 & 4.0 & 41.5 & 791 \\
\hline $20-24$ & 23.3 & 13.5 & 36.8 & 1761 \\
\hline \multicolumn{5}{|l|}{ Age at marriage } \\
\hline Below 20 & 26.8 & 11.7 & 38.5 & 2152 \\
\hline 20 and above & 32.9 & 4.3 & 37.2 & 400 \\
\hline \multicolumn{5}{|l|}{ Number of living children } \\
\hline No Child & 34.5 & 0.9 & 35.4 & 828 \\
\hline 1 & 32.2 & 9.3 & 41.5 & 1000 \\
\hline $2+$ & 13.9 & 23.4 & 37.3 & 725 \\
\hline \multicolumn{5}{|l|}{ Presence of son } \\
\hline No Son & 33.8 & 4.3 & 38.1 & 1491 \\
\hline Having at least one son & 19.2 & 19.3 & 38.5 & 1062 \\
\hline \multicolumn{5}{|l|}{ Women's education } \\
\hline No education & 20.8 & 9.8 & 30.6 & 684 \\
\hline Primary & 26.9 & 14.0 & 40.9 & 588 \\
\hline Secondary and higher & 31.8 & 9.4 & 41.2 & 1281 \\
\hline \multicolumn{5}{|l|}{ Women's occupation } \\
\hline Not working & 29.6 & 9.6 & 39.2 & 840 \\
\hline Agriculture & 28.9 & 11.7 & 40.6 & 1403 \\
\hline Non agriculture & 17.5 & 7.7 & 25.2 & 309 \\
\hline \multicolumn{5}{|l|}{ Household economic status } \\
\hline Poorer & 27.3 & 11.2 & 38.5 & 976 \\
\hline Middle & 31.5 & 8.9 & 40.4 & 623 \\
\hline Richer & 25.7 & 10.9 & 36.6 & 954 \\
\hline $\begin{array}{l}\begin{array}{l}\text { Assets } \\
\text { house) }\end{array} \\
\text { ownership (land and }\end{array}$ & & & & \\
\hline No & 28.1 & 10.2 & 38.3 & 2458 \\
\hline Yes & 18.2 & 19.5 & 37.7 & 94 \\
\hline \multicolumn{5}{|l|}{ Women empowerment status } \\
\hline Not empowered & 30.8 & 9.0 & 39.8 & 1749 \\
\hline Empowered & 21.0 & 13.9 & 34.9 & 793 \\
\hline \multicolumn{5}{|l|}{ Caste/ethnicity } \\
\hline Brahmin/chhetri & 27.8 & 11.2 & 39.0 & 735 \\
\hline Janajati & 25.8 & 11.9 & 37.7 & 943 \\
\hline Dalit & 33.5 & 11.3 & 44.8 & 483 \\
\hline Others & 25.0 & 5.1 & 30.1 & 392 \\
\hline \multicolumn{5}{|l|}{ Ecological zone } \\
\hline Mountain & 23.9 & 9.2 & 33.1 & 172 \\
\hline Hill & 29.2 & 11.8 & 41.0 & 954 \\
\hline Tarai & 27.2 & 9.9 & 37.1 & 1426 \\
\hline \multicolumn{5}{|l|}{ Place of residence } \\
\hline Urban & 20.2 & 6.8 & 27.0 & 253 \\
\hline Rural & 28.5 & 10.9 & 39.4 & 2300 \\
\hline Total & 27.7 & 10.5 & 38.2 & 2552 \\
\hline
\end{tabular}

Source: NDHS 2011 Data File.

Note: Chi- square test shows all the variable are statistically significant at $<005$. 
Table 1 presents the results of the bivariate analysis between the young women's socioeconomic, demographic and individual characteristics and unmet need for family planning. It shows how young women's unmet need for spacing and limiting vary according to demographic and socioeconomic characteristics like age of respondent, age at first marriage/cohabitation, number of living children, presence of son, education, and occupation, access to assets, household economic status, empowerment status, caste/ethnicity and place of residence.

The level of unmet need for spacing is relatively high as compared to that of limiting because the study populations are teenagers who hold hope of bearing children in future. Thirty eight percent of young women have total unmet need of contraception in Nepal that means about two in four Nepalese young women do not wish to conceive or wish to limit or space their pregnancies but fails to realize these intentions. The results indicate that adolescent married women age 15-19 experience greater unmet need (41.5\%) than do married women age 20-24 (36.8\%). Unmet need increases with parity and no differences are marked between young married women having no son and those with at least one son. Unmet need for spacing decreases and unmet need for limiting increases as the number of living children increases. In this study both unmet need for spacing and total unmet need are increasing with increased education level of young women.

Unmet need for spacing, limiting as well as total unmet need are significantly low among young women who work in non agricultural sectors than that of not working women. The unmet need does not differ much with household economic status and asset ownership status of female. The total unmet need for contraception is found to be higher among Dalit women (44.8\%), among Hill women (41.0\%) and rural women (39.4\%).

\subsection{Unmet need for family planning among young women: Multivariate analysis}

Multivariate logistic regression analyses are done by impulsively fitting all the variables that were found to be significantly associated with the overall unmet need in the multivariate logistic regression model and results are shown in Table 2. For total unmet need for family planning both gross and net effect are applied in order to show the association between the unmet need of young women and each of the predictor variables before and after controlling the effect of the other predictor variables. In this study, an attempt has been made to examine the effects of different determining variables on unmet need of contraception and identify a number of factors that have important influences on young women unmet need in Nepal.

Many studies and policies have been based on the assumption that if women are more educated, involved in household decision making and have more control over financial resources, they would be more likely to be empowered and have more command in the contraceptive methods choice and utilization. However, results from this study reveal a more insight picture, showing relationships between unmet need of young women and indicators of explanatory variables.

From the Table 2, we see that the significant explainers of unmet need are age of the woman, her number of living children, education, occupation, empowerment status, caste/ethnic affiliation and place of residence. Unmet need for family planning is lower among women of aged 20-24 years $(\mathrm{OR}=0.78)$ as compared to women aged $15-19$ years. It indicates that demand for contraception is high among the adolescent women. 
Table 2: Unadjusted (gross effect) and adjusted (net effect) odds ratios for total unmet need for family planning

\begin{tabular}{|c|c|c|c|c|c|c|}
\hline \multirow[b]{3}{*}{ Variables } & \multicolumn{3}{|c|}{ Model I (Gross effect) } & \multicolumn{3}{|c|}{ Model II (Net effect) } \\
\hline & \multirow{2}{*}{$\begin{array}{l}\text { Odds } \\
\text { ratio }\end{array}$} & \multicolumn{2}{|c|}{ 95\% CI for OR } & \multirow{2}{*}{$\begin{array}{l}\text { Odds } \\
\text { ratio }\end{array}$} & \multicolumn{2}{|c|}{ 95\% CI for OR } \\
\hline & & Lower & Upper & & Lower & Upper \\
\hline \multicolumn{7}{|l|}{ Age groups } \\
\hline $15-19(\mathrm{R})$ & 1.0 & & & 1.0 & & \\
\hline $20-24$ & $0.823 * *$ & 0.694 & 0.977 & $0.784 * *$ & 0.627 & 0.981 \\
\hline \multicolumn{7}{|l|}{ Age at marriage } \\
\hline Below 20 & 1.0 & & & & & \\
\hline 20 and above & 0.947 & 0.760 & 1.180 & 1.167 & 0.893 & 1.526 \\
\hline \multicolumn{7}{|c|}{ Number of living children } \\
\hline No Child(R) & 1.0 & & & 1.0 & & \\
\hline 1 & $1.293 * * *$ & 1.069 & 1.564 & $1.488 * * *$ & 1.179 & 1.879 \\
\hline $2+$ & 1.084 & 0.881 & 1.334 & $1.624 * * *$ & 1.185 & 2.225 \\
\hline \multicolumn{7}{|l|}{ Presence of son } \\
\hline No Son $(\mathrm{R})$ & 1.0 & & & 1.0 & & \\
\hline Having at least one son & 1.014 & 0.862 & 1.192 & 0.921 & 0.744 & 1.139 \\
\hline \multicolumn{7}{|l|}{ Women's education } \\
\hline No education $(R)$ & 1.0 & & & 1.0 & & \\
\hline Primary & $1.568 * * *$ & 1.244 & 1.976 & $1.575^{* * *}$ & 1.234 & 2.005 \\
\hline Secondary and higher & $1.587 * * *$ & 1.303 & 1.933 & $1.905 * * *$ & 1.490 & 2.435 \\
\hline \multicolumn{7}{|l|}{ Women's occupation } \\
\hline Not working(R) & 1.0 & & & 1.0 & & \\
\hline Agriculture & 1.063 & 0.893 & 1.267 & 0.873 & 0.705 & 1.081 \\
\hline Non agriculture & $0.525 * * *$ & 0.392 & 0.703 & $0.462 * * *$ & 0.336 & 0.635 \\
\hline \multicolumn{7}{|c|}{ Household economic status } \\
\hline Poorer (R) & 1.0 & & & 1.0 & & \\
\hline Middle & 1.078 & 0.878 & 1.324 & 1.135 & .904 & 1.425 \\
\hline Richer & 0.919 & 0.764 & 1.104 & 1.028 & 0.797 & 1.327 \\
\hline \multicolumn{7}{|c|}{ Assets ownership (land and house) } \\
\hline No $(\mathrm{R})$ & 1.0 & & & 1.0 & & \\
\hline Yes & $4.150 * * *$ & 3.536 & 4.825 & 1.131 & 0.719 & 1.327 \\
\hline \multicolumn{7}{|c|}{ Women empowerment status } \\
\hline Not empowered(R) & 1.0 & & & 1.0 & & \\
\hline Empowered & 0.973 & 0.636 & 1.488 & $0.821 *$ & 0.679 & 0.993 \\
\hline \multicolumn{7}{|l|}{ Caste/Ethnicity } \\
\hline Brahmin/Chhetri (R) & 1.0 & & & 1.0 & & \\
\hline Janajati & 0.948 & 0.777 & 1.156 & 0.937 & 0.759 & 1.157 \\
\hline Dalit & $1.272 * *$ & 1.008 & 1.605 & $1.421 * * *$ & 1.094 & 1.844 \\
\hline Others & $0.674 * * *$ & 0.519 & 0.876 & $0.703 * *$ & 0.511 & 0.966 \\
\hline \multicolumn{7}{|l|}{ Ecological Zone } \\
\hline Mountain (R) & 1.0 & & & 1.0 & & \\
\hline Hill & $1.407 *$ & 0.999 & 1.983 & $1.459 *$ & 1.022 & 2.081 \\
\hline Tarai & 1.193 & 0.853 & 1.668 & 1.248 & 0.864 & 1.802 \\
\hline \multicolumn{7}{|l|}{ Place of Residence } \\
\hline Urban (R) & 1.0 & & & 1.0 & & \\
\hline Rural & $1.757 * * *$ & 1.315 & 2.348 & $1.738 * * *$ & 1.267 & 2.383 \\
\hline
\end{tabular}

Source: NDHS 2011 Data File.

$* * *$ Significant at 1 percent level, ** Significant at 5 percent level and $*$ Significant at 10 percent level, (R) Reference category

In both model unmet need for contraception is higher among the young women who have secondary and more level of education (unadjusted $\mathrm{OR}=1.58$ and adjusted $\mathrm{OR}=1.49$ ) compared to uneducated women. Young women working in non agricultural field, empowered in decision making, and residing in urban areas are less likely to experience unmet need for contraception unlike their counterparts with not working and working in agricultural field, not empowered and those with living in rural areas. The study finds out 
that women who work in non agricultural sector are 54 percent less likely, at $\rho<0.01$, to report unmet need when compared to not working women. Similarly empowered women in terms of household decision making matters are 20 percent less likely to report unmet need as compared to not empowered women. The result of both models explains Dalits young women are more likely to report unmet need for contraception as compared to Brahmin/Chhetri women. The analytical results in Table 2 indicate that unmet need is high among young women who are residents of Hill region (adjusted $\mathrm{OR}=1.46$ ) and rural areas (adjusted $\mathrm{OR}=$ 1.74) as compared to women residents of Mountain region and urban areas.

\section{Concluding Remarks}

This study examines prevalence and determinants of unmet need for family planning services among currently married young women of aged 15-24 years in Nepal. The study shows that the total unmet need for family planning among young women is 38 percent which is much higher than the current national unmet need for family planning of 27 percent among all women of reproductive age according to the NDHS 2011 report. The study findings show that age of the woman, her number of living children, education, occupation, empowerment status, caste/ethnic affiliation and place of residence are statistically associated to unmet need for family planning among young women in Nepal.

Unmet need for family planning is significantly lower among youth (20-24) as compared with adolescent women aged 15-19. Young women (15-19 years) do have unmet need probably due to lack of knowledge on contraceptives. In contrast to other studies (Hameed, Azmat, Bilgrami \& Ishaqe, 2011; Klijzing, 2000) which found unmet need for family planning increasing with age, this study demonstrates the reverse finding with young adult women (20-24) less likely to have total unmet need compared to those aged 15-19.These findings support the claim that young people are among the groups most likely to have unmet need for family planning (Ojakaa, 2008) because they are sexually active, and more desirous of avoiding pregnancy, but are not using modern methods of contraception (United Nations, 2011).

This study also finds unmet need for family planning to be higher among women with higher number of living children than among women with one or no child. This confirms findings from previous studies (Hameed et al., 2011; Khan, Bradley Sarah, Fishel \& Mishra 2008). The higher likelihood of unmet need for family planning among women with higher number of living children therefore suggests more of unmet need for limiting than for spacing births (Klijzing, 2000).

It is generally accepted that educational level plays an important role in shaping unmet need for family planning (Hailemariam and Haddis, 2011, Acacio-Claro and Borja, 2010, Ali and Okud, 2013, Ojakaa, 2008). Women with higher education are found to be less likely to have unmet need for spacing, limiting and total unmet need for family planning as observed in Eastern Sudan (Ali and Okud, 2013). Women who attained higher level education had more knowledge because they are more exposed to family planning through media and other modes of exposure and also because they spend most of their time in school, they start childbearing late (Wolff, Blanc and Gage, 2000). But the present study shows the reverse result and found that women with primary and secondary education were more likely to have unmet need for family planning. This might be due to the accelerated expansion of education and school based family planning programmes in recent years that have raised the awareness of family planning in the youth thereby increasing the unmet need for contraception among women.

With regard to occupation, women in this study, who were currently working in non agricultural sector are less likely to have unmet need for family planning. This study supports the findings from studies in Ethiopia (Hailemariam \& Haddis, 2011), Kenya (Ojakaa, 2008) and Eastern Sudan (Ali and Okud, 2013) which showed that total unmet need decreases with women's employment. 
According to theories of women's empowerment and evidence from some studies, equity in household decision-making is associated with positive outcomes in various spheres, including health (Hou\& Ma, 2011;Woldemicael\&Beaujot, 2011). This perspective is confirmed by this study as the finding shows the statistically significant association between the number of decisions a woman can make in the household and unmet need for family planning.

Generally, public health and economic significance of the burden of unmet need demonstrated by findings of this study can be generalized to the large size of young women represented by - female adolescents; women not currently working; educated young women; women with high parity; women who are from Dalit family; and women in rural areas.

Women's current age, number of living children, education level, occupation, women empowerment, caste/ethnic affiliation, and residence are independent predictors of unmet need. The odds of unmet need are significantly higher among the adolescents, rural, not empowered and not working young women. There is need to strengthen income generating activities so as to improve their socio-economic status which will translate into female economic and social empowerment hence ability to discuss sexuality related issues. Family planning programmes should be designed so as to address the unmet need of young women especially the rural adolescents. Qualitative research would help to better understand the barriers to unmet need for family planning in Nepal. Additionally, the impact of providing family planning services during maternal and child health services need further evaluation.

\section{Reference}

Acacio-Claro, P. J. B. \& Borja, M. P. (2010). Addressing unmet need: Potential for increasing contraceptive prevalence in the Philippines. Asia-Pacific Population Journal, 25(20), 5-26.

Ali, A. A. A. \& Okud, A. (2013). Factors affecting unmet need for family planning in Eastern Sudan. BMC Public Health, 13, 1-5.

Ashford, L. (2003). Unmet need for family planning: Recent trends and their implications for programs. Washington, DC: Population Reference Bureau.

Borda, M., \& Winfrey, W. (2010). Postpartum fertility and contraception: an analysis of findings from 17 countries. Baltimore: Jhpiego.

Central Bureau of Statistics (CBS). (2015). Nepal multiple indicator cluster survey 2014: Final report. Kathmandu, Nepal: Central Bureau of Statistics and UNICEF Nepal.

Cleland, J. \& Ali, M.(2004). Reproductive consequences of contraceptive failure in 19 developing countries. Obstetrics and Gynecology, 104(2), 314-320.

Desgrees-Du-Lou and Brou H., (2005). Resumption of sexual relations following childbirth: norms, practices and reproductive health issues in Abidjan. Reproductive Health Matters, 13(25), $155-163$.

Foran, T. (2011). Post- partum contraception. Australian Doctor, (9), 35-37.

Hailemariam, A. \& Haddis, F. (2011). Factors affecting unmet need for family planning in Southern Nations, Nationalities and Peoples Region, Ethiopia. Ethiopian Journal of Health Science, 21 (2), 77-89.

Hameed, W., Azmat, S. K., Bilgrami, M. \& Ishaqe, M. (2011). Determining the factors associated with unmet need for family planning : A cross-sectional survey in 49 districts of Pakistan. Pakistan Journal of Public Health, 1(1), 21-27.

Hou, X.,\& Ma, N. (2011). Empowering women: The effect of women's decision-making power on reproductive health services uptake: Evidence from Pakistan (Working Papers and Research Publications). Washington, DC: The World Bank.

Ijadunola, E. O; Orji, O. Kuti, \& Alabi M. M. (2005). The unmet need for contraception among Nigerian women in the first year post-partum. European Journal of Contraception and Reproductive Health Care, 10 (4), 229-234. 
Jejeebhoy, S. J., Santhya, K.G.,\& Francis Zavier A.J. (2014). Demand for contraception to delay first pregnancy among young married women in India. Studies in Family Planning, 45(2), 183-201.

Khan S, Bradley Sarah E.K., Fishel, J. \& Mishra, V. (2008). Unmet need and the demand for family planning in Uganda: Further analysis of the Uganda Demographic and Health Surveys, 1995-2006. Calverton, Maryland, USA: Macro International Inc.

Klijzing, E. (2000). Are there unmet family planning needs in Europe? Family Planning Perspectives, $32,74-81 \& 88$.

MacQuarrie, Kerry L.D. (2014). Unmet need for family planning among young women: Levels and trends. DHS Comparative Reports No. 34. Rockville, Maryland, USA: ICF International.

Ministry of Health (MoH). (2015). National family planning costed implementation plan 2015 2020. Kathmandu: MoH.

Ministry of Health (MOH) [Nepal], New ERA, and ICF. (2017). Nepal demographic and health survey 2016. Kathmandu: Ministry of Health.

Ministry of Health (MoH)/ Department of Health Services (DoHS). (2015/16). Annual health report 2015/16. Kathmandu: MoH, Department of Health Services.

Ministry of Health and Population (MOHP) [Nepal], New ERA, and ICF International Inc. (2012). Nepal demographic and health survey 2011. Kathmandu: Ministry of Health and Population, New ERA, and ICF International, Calverton, Maryland.

Nyauchi, B. \& Omedi, G. (2014). Determinants of unmet need for family planning among women in rural Kenya. African Population Studies, 28 (2), Supplement.

Ojakaa, D. (2008). Trends and determinants of unmet need for family planning in Kenya. DHS Working Papers 56. Nairobi, Kenya: Macro International Inc.

Okech, T.C., Wawire, N.W. \& Mburu, T.K. (2011) Contraceptive use among women of reproductive age in Kenya's City Slums. International Journal of Business and Social Science 2, 22-43.

Ross, J. (1994). Program implementation of the unmet need approach. Paper presented at the 1994 Annual Meeting of the Population Association of America, Miami, Florida.

Sinding, S. W., John A. R, and Rosenfield A. G. (1994). Seeking common ground: Unmet need and demographic goals. International Family Planning Perspectives 20(1), $23-$ 27.

United Nations (2011). The millenium development goals report 2011. New York: United Nations

United Nations Population Fund [UNFPA]. (2004). Programme of action: Adopted at international conference on population and development, Cairo (5-13 September 1994). New York: UNFPA.

United Nations, (2017). World contraceptive use by marital status and age 2017. New York: United Nations.

Vernon, R. (2009). Meeting the family planning needs of postpartum women. Studies in Family Planning, 40(3), 235-245.

Westoff, C. F., (2006). New estimates of unmet need and the demand for family planning (DHS Comparative Reports No. 14). Calverton, MD: Macro International.

Westoff, C.F \& Pebley A.R. (1981). Alternative measures of unmet need for family planning in developing countries. International Family Planning Perspectives, 7(4), 126-136.

Woldemicael, G., and Beaujot, R. (2011). Currently married women with an unmet need for contraception in Eritrea: Profile and determinants. Canadian Studies in Population, 38 (1-2), $61-81$.

Wolff, B., Blanc, A. K., \& Gage, A. J. (2000). Who decides? Women's status and negotiation of sex in Uganda. Culture, Health \& Sexuality, 2(3), 303-322.

World Health Organization. (WHO). (2011). Family Planning. Retrieved from:http:// www.who.int/topics/familyplanning.

Note: Views and opinions expressed in this article are the personal views of author 